\title{
Genetic variation in vascular endothelial growth factor gene and its association with recurrent spontaneous abortion
}

\author{
Saboori $\mathrm{S}^{1}$, Noormohammadi $\mathrm{Z}^{1}$, Zare-Karizi $\mathrm{S}^{2}$ \\ Department of Biology, School of Sciences, Science and Research Brach, Islamic Azad University, \\ Tehran,Iran.z-nouri@srbiau.ac.ir
}

\begin{abstract}
BACKGROUND: Vascular endothelial growth factor (VEGF) plays a main role in fetal and placental angiogenesis and is secreted by different cells of endometrium and placenta.

OBJECTIVE: In the present study we investigated the association of VEGF gene polymorphisms with recurrent spontaneous abortion (RSA).

METHODS: A case-control study of 100 women with at least two consecutive pregnancy losses before 20 weeks of gestational age and 100 fertile controls was performed to evaluate four VEGF gene polymorphisms including + 936C/T (rs3025039), -154G>A (rs1570360), rs3025010 and +5092A/C (rs2146323). Genotyping was performed by PCR based restriction fragment length polymorphism (PCR-RFLP) analysis. Haplotype frequency was estimated for three SNPs' genotypes. Analysis of genetic STRUCTURE and K means clustering were performed to estimate genetic variation.

RESULTS: We found an association between -154G/A heterozygous genotype (GA) and RSA. The VEGF single nucleotide polymorphism (SNP) in intron region (rs3025010) in different inheritance models was also associated with RSA. Linkage disequilibrium analysis revealed that VEGF SNP in intron 5 (rs3025010) was linked to promoter region SNP (rs1570360). Cluster analysis including Neighbor Joining and K-means clustering supported genetic differentiation of women with RSA and controls.

CONCLUSION: Allelic polymorphisms in common VEGF SNPS was associated with RSA samples and haplotypes with at least one minor allele showing an association with RSA pathogenesis (Tab. 8, Fig. 2, Ref. 35). Text in PDF www.elis.sk.

KEY WORDS: genetic diversity, haplotype, K means, VEGF gene, RSA.
\end{abstract}

\section{Introduction}

A successful pregnancy requires several components that regulate the interaction between mother and fetus. Recurrent spontaneous abortion (RSA) is one of the reproductive problems which affects approximately $1 \%$ of couples trying to conceive $(1,2)$. In literatures, several factors have been reported to contribute to RSA pathogenesis such as chromosomal abnormalities, autoimmune disorders, endocrinopathies, women lifestyle like obesity, smoking and diet (3-6). Despite of these records, etiology of RSA (up to $50 \%$ of cases) remains undetermined and it is likely to be multifactorial (7).

The vascular endothelial growth factor (VEGF) is a pivotal mediator of angiogenesis and vasculogenesis (8). VEGF plays a main role in fetal and placental angiogenesis and is secreted by

\footnotetext{
${ }^{1}$ Department of Biology, School of Sciences, Science and Research Brach, Islamic Azad University, Tehran, Iran, and ${ }^{2}$ Department of Biology, Varamin Branch, Islamic Azad University, Varamin, Iran
}

Address for correspondence: Z Noormohammadi, Department of Biology, School of Sciences, Science and Research Brach, Islamic Azad University, Tehran, Iran.

Phone: +98.21.44865939, Fax: +98.21.44865767

Acknowledgment: We gratefully acknowledge Science and Research Branch, Islamic Azad University for supporting this study. We also thank Dr. Mohamad-Taghi Akbri who provided samples for this study. different cells of endometrium, placenta as well as endothelial cells and vascular smooth muscle cells $(9,10)$. VEGF family consists of VEGF, VEGF-B, VEGF-C, VEGF-D and placental growth factor (PIGF), they bind to three receptors, VEGFR-1, VEGFR-2 and VEGFR-3, found on the vascular endothelium (10). The VEGF gene is located on human chromosome $6 \mathrm{p} 21.3$ and contains eight exons and seven introns forming several VEGF isoforms by alternative splicing in different cells (11). The several common VEGF polymorphism sites in promoter $(-2578 \mathrm{C} / \mathrm{A},-1154 \mathrm{G} / \mathrm{A},-254918$ bp I/D, -460C/T, -1498T/C, -1190G/A), the 5'UTR (-634G/C, -7T/ C ), the 3'UTR (+936C/T and +1612G/A) and intron (rs3025010) regions have been reported by various studies on RSA women of differrent ethnicities (12-19).

With regard to the population's genetic diversity, Ruggiero et al (20) carried out a genome-wide linkage analysis (77 SNPs including 64 SNPs and $13 \mathrm{Ins} / \mathrm{Del}$ ) in three Italian isolated populations and detected linkage between VEGF serum levels and 6p21.1 VEGF region. Three common single nucleotide polymorphisms (SNPs) including rs3025039, rs25648, rs3025020 in one population and rs41282644 in another population were found to affect the VEGF serum levels.

In the present study, our aim was to study genetic variation of VEGF gene and also the association of four common VEGF SNPs with RSA in Iranian women and fertile controls. 


\section{Materials and methods}

\section{Study design and participants}

Our study was designed in two parts: 1 - case-control study design to compare VEGF polymorphism among individuals with RSA and controls, 2 - SNP genotyping to evaluate genetic diversity of VEGF genein the studied female population. Women (age range, $17-45$ years; mean age $\pm \mathrm{SD}, 28 \pm 5.22$ years) who were diagnosed with idiopathic recurrent spontaneous abortion (RSA) with at least two consecutive pregnancy losses before 20 weeks of gestational age (range of abortion number 2-6; mean abortion No $\pm \mathrm{SD}, 2.2 \pm 0.99$ ) according to the ASRM definition (21) were selected. Patients who suffered from chromosomal abnormality like translocation, trisomy and triploidy were excluded from the study group and finally 100 samples selected for further study. Hundred women with the same age range (17-45) with regular menstrual cycles and at least one natural pregnancy with normal karyotype were chosen as a control group. All samples were collected from Tehran Medical Genetic Center from 2010 to 2011 and patients provided written informed consent. This study was approved by a local ethical committee based on rules and regulations of Iranian Ministry of Health.

\section{Analysis of VEGF polymorphism}

Genomic DNA was extracted from EDTA anticoagulated peripheral blood by using standard salting-out procedure. The quantity and quality of extracted DNA were examined by Nanodrop spectrophotometer and $0.8 \%$ agaros gel electrophoresis, respectively.

Four common VEGF SNPs located in 3'UTR region + 936C/T (rs3025039), promoter region $-154 \mathrm{G}>\mathrm{A}$ ( $\mathrm{rs} 1570360)$, and intron region (rs3025010, intron 5) and $+5092 \mathrm{~A} / \mathrm{C}$ (rs2146323, intron 2) were selected and oligonucleotide primers were designed based on published sequence of human VEGF gene by using Gene Runner ver. 3.05 software (Tab. 1). The genotyping was performed by PCR based restriction fragment length polymorphism (PCRRFLP) analysis. Restriction enzymes were selected for each SNP by using NEBcutter program (Tab. 1).

PCR was carried out in a total of $25 \mu 1$ volume containing 50 ng of the genomic DNA, 1x PCR buffer, $0.23 \mathrm{mM}$ dNTP-Mix, 6 pmol of each primer, $1.3 \mathrm{mM} \mathrm{MgCl} 2$ and $1 \mathrm{U} / \mu 1$ Taq DNA polymerase. Thermal cycler program was performed for $5 \mathrm{~min}$ at $95^{\circ} \mathrm{C}$ as initiation denaturation following 30 cycles of $1 \mathrm{~min}$ at $95^{\circ} \mathrm{C}$, $1 \mathrm{~min}$ at annealing temperature based on primer pairs (Tab. 1) and $1 \mathrm{~min}$ in $72{ }^{\circ} \mathrm{C}$ with final extension at $72{ }^{\circ} \mathrm{C}$ for $10 \mathrm{~min}$. PCR products were digested according to manufacturer procedures (Fermentas) and incubated at proper temperature and time. Allele profiles were visualized by running on $12 \%$ poly acryl amide gel electrophoresis (PAGE) following staining with Syber Green gel stain. We used 100bp DNA Ladder Plus (Fermentas) as size marker.

\section{Statistical analysis}

Differences in three SNPs' frequencies were evaluated between control and case samples by using $\chi^{2}$ or Fisher's exact test. Gene polymorphisms were analyzed for Hardy-Weinberg equilibrium. We further used crude odds ratio (COR) and $95 \%$ confidence interval (CI) for calculating the association between genotypes and recurrent spontaneous abortion by logistic regression analysis. We considered $\mathrm{P}$ value $<0.05$ to be statistically significant. Other inheritance models like Akaike's Information Criterion (AIC) and Bayesian Information Criterion (BIC) were calculated for the selection of the best model for a specific SNP.

Haplotype frequency of four SNPs' genotypes as well as haplotype association between control and case samples were estimated using SNPstats software (22). In the present study, for linkage disequilibrium (LD) of four SNPs studied, selected statistics ( $\mathrm{D}^{\prime}$, Pearson's $r$ and associated $p$ - value) between each pair of SNPs were analysed by SNPAlyze 7.0.Pro software (DYNACOM Co., Ltd., Yokohama, Japan).

In order to estimate genetic variation of VEGF gene, alleles of each genotype obtained were treated as binary characters and coded accordingly (presence $=1$, absence $=0$ ). The genetic diversity parameters were determined in population by using GenAlex Ver. 6.4 program. These parameters were percentage of allelic polymorphism, allele diversity (23), Nei's gene diversity (H), Shannon information index (I) (23), the number of effective alleles and the percentage of polymorphism.

Dice as well as the Nei's genetic distance (23), were determined among the studied case and control samples. These distances were used for the grouping of individuals by unweighted paired group method with arithmetic average (UPGMA) and Neighbor Joining (NJ) clustering methods after 100 times of bootstrapping (23).

The AMOVA (Analysis of Molecular Variance) test was performed to show the genetic difference among the studied groups (with 1000 permutations) as performed by GenAlex ver. 6.4 .

Tab. 1. Primer sequences designed for four SNPs of VEGF gene with their PCR length and annealing temperature ( $\left.T_{a}\right)$.

\begin{tabular}{|c|c|c|c|c|}
\hline KDR gene (SNP) & Primer sequence $\left(5^{\prime} \rightarrow 3^{\prime}\right)$ & PCR product length $(\mathrm{bp})$ & $\mathrm{T}_{\mathrm{a}}$ & Restriction Enzyme \\
\hline $\begin{array}{l}+936 \mathrm{C} / \mathrm{T} \\
\text { (rs3025039, 3'UTR region) }\end{array}$ & $\begin{array}{l}\text { F-CACCACACCATCACCATCGAC } \\
\text { R-TATGTGGGTGGGTGTGTCTACAG-3, }\end{array}$ & 250 & 58 & NlaIII \\
\hline $\begin{array}{l}-1154 \mathrm{G}>\mathrm{A} \\
\text { rs1570360, up stream } \\
\text { variant, promoter region) }\end{array}$ & $\begin{array}{l}\text { F- GCGTGTCTCTGGACAGAGTTTC } \\
\text { R-ATATCAAATTCCAGCACCGAG }\end{array}$ & 405 & 60 & MnlI \\
\hline intron $5 \mathrm{C} / \mathrm{T}$ (rs3025010) & $\begin{array}{l}\text { F- TTGGTGCTTTCTCCTAAGGG } \\
\text { R-AGCCTGCTACACCATCTCACC }\end{array}$ & 250 & 58 & HaeIII \\
\hline $\begin{array}{l}+5092 \mathrm{~A} / \mathrm{C} \\
\text { (rs2146323, intron 2), }\end{array}$ & $\begin{array}{l}\text { F- CATGCCCTTGGAACTTGAGTAC } \\
\text { R- CGCTGATAGACATCCATGAACTTC }\end{array}$ & 271 & 62 & EcoRI \\
\hline
\end{tabular}


80-86

Tab. 2. Allele and genotype frequencies in case and control samples in four VEGF SNPs studied. *MAF = minor allele frequency.

\begin{tabular}{|c|c|c|c|c|c|c|c|}
\hline \multirow{2}{*}{$\begin{array}{l}\text { VGEF SNP } \\
\text { Allele/Genotype }\end{array}$} & \multicolumn{2}{|c|}{ All subjects } & \multicolumn{2}{|c|}{ Case } & \multicolumn{2}{|c|}{ Control } & \multirow{2}{*}{$\mathrm{X}^{2}$ (p-value) } \\
\hline & Count & Proportion & Count & Proportion & Count & Proportion & \\
\hline \multicolumn{8}{|l|}{ rs3025039 } \\
\hline $\bar{C}$ & 370 & 0.92 & 183 & 0.92 & 187 & 0.94 & \multirow{4}{*}{$0.627(0.56)$} \\
\hline $\mathrm{T}^{*}$ & 30 & 0.08 & 17 & 0.08 & 13 & 0.06 & \\
\hline $\mathrm{CC}$ & 170 & 0.85 & 83 & 0.83 & 87 & 0.87 & \\
\hline $\mathrm{CT}$ & 30 & 0.15 & 17 & 0.17 & 13 & 0.13 & \\
\hline \multicolumn{8}{|l|}{ rs 1570360} \\
\hline $\bar{G}$ & 366 & 0.92 & 170 & 0.85 & 196 & 0.98 & \multirow{4}{*}{$23.95(<0.000)$} \\
\hline$A^{*}$ & 34 & 0.08 & 30 & 0.15 & 4 & 0.02 & \\
\hline GA & 34 & 0.17 & 30 & 0.3 & 4 & 0.04 & \\
\hline GG & 166 & 0.83 & 70 & 0.7 & 96 & 0.96 & \\
\hline \multicolumn{8}{|l|}{ rs3025010 } \\
\hline$\overline{\mathrm{T}}$ & 283 & 0.71 & 136 & 0.68 & 147 & 0.74 & \multirow{4}{*}{$5.945(0.049)$} \\
\hline $\mathrm{C}^{*}$ & 117 & 0.29 & 64 & 0.32 & 53 & 0.26 & \\
\hline $\mathrm{TC}$ & 95 & 0.48 & 56 & 0.56 & 39 & 0.39 & \\
\hline TT & 94 & 0.47 & 40 & 0.4 & 54 & 0.54 & \\
\hline \multicolumn{8}{|l|}{ rs2146323 } \\
\hline $\mathrm{C}$ & 400 & 1 & 200 & 1 & 200 & 1 & \multirow[t]{2}{*}{--} \\
\hline $\mathrm{A}^{*}$ & 0 & 0 & 0 & 0 & 0 & 0 & \\
\hline
\end{tabular}

Tab. 3. inheritance models of VEGF SNPs and odds ratio (OR) with 95\% confidential interval between case and controls. Akaike's Information Criterion (AIC) and Bayesian Information Criterion (BIC).

\begin{tabular}{|c|c|c|c|c|c|c|c|}
\hline Model & Genotype & Case & Control & OR $(95 \% \mathrm{CI})$ & $\mathrm{P}$-value & AIC & $\mathrm{BIC}$ \\
\hline \multicolumn{8}{|l|}{ rs3025039 } \\
\hline \multirow[t]{2}{*}{--} & $\mathrm{CC}$ & $83(83 \%)$ & $87(87 \%)$ & 1.00 & 0.43 & 280.6 & 287.2 \\
\hline & $\mathrm{CT}$ & $17(17 \%)$ & $13(13 \%)$ & $0.73(0.33-1.60)$ & & & \\
\hline \multicolumn{8}{|l|}{ rs 1570360} \\
\hline \multirow[t]{2}{*}{--} & GG & $70(70 \%)$ & $96(96 \%)$ & 1.00 & $<0.0001$ & 254.7 & 261.3 \\
\hline & $\mathrm{AG}$ & $30(30 \%)$ & $4(4 \%)$ & $0.01(0.03-0.29)$ & & & \\
\hline \multicolumn{8}{|l|}{ rs3025010 } \\
\hline \multirow[t]{3}{*}{ Codominant } & TT & $40(40 \%)$ & $54(54 \%)$ & 1.00 & 0.05 & 277.3 & 287.2 \\
\hline & CT & $56(56 \%)$ & $39(39 \%)$ & $0.52(0.29-0.92)$ & & & \\
\hline & $\mathrm{CC}$ & $4(4 \%)$ & $7(7 \%)$ & $1.30(0.36-4.73)$ & & & \\
\hline \multirow[t]{2}{*}{ Dominant } & TT & $40(40 \%)$ & $54(54 \%)$ & 1.00 & 0.047 & 277.3 & 287.2 \\
\hline & CT-CC & $60(60 \%)$ & $46(46 \%)$ & $0.54(0.32-1)$ & & & \\
\hline \multirow[t]{2}{*}{ Recessive } & TT-CT & $96(96 \%)$ & $93(93 \%)$ & 1.00 & 0.35 & 280.4 & 287.0 \\
\hline & $\mathrm{CC}$ & $4(4 \%)$ & $7(7 \%)$ & $1.81(0.51-6.31)$ & & & \\
\hline \multirow[t]{2}{*}{ Overdominant } & TT-CC & $44(44 \%)$ & $61(61 \%)$ & 1.00 & 0.016 & 275.4 & $283-0$ \\
\hline & $\mathrm{CT}$ & $56(56 \%)$ & $39(39 \%)$ & $0.5(0.29-0.88)$ & & & \\
\hline Log-additive & --- & --- & --- & $0.73(0.46-1.17)$ & 0.19 & 279.5 & 286.1 \\
\hline
\end{tabular}

The genetic structure of case and control samples and k-means clustering were studied by STRUCTURE analysis and GenoDive ver.2 (2013). The STRUCTURE Harvester web site (24) was used to visualize the STRUCTURE results and also to perform Evanno method to identify proper number of $\mathrm{K}(25)$. We used two summary statistics to present K-Means clustering, 1- pseudo-F and 2- Bayesian Information Criterion. Pseudo-F relates $\mathrm{r}^{2}$, the fraction of the total variance that is explained by the clustering. The clustering with the highest value for pseudo-F is regarded to provide the best fit (26).

\section{Results}

Allele and genotypes distribution of four VEGF SNPs are listed in Table 2. The genotype distributions of $\mathrm{rs} 3025039$ ( $\mathrm{p}=$
1.0), rs1570360 ( $\mathrm{p}=1.0)$ and $\mathrm{rs} 3025010(\mathrm{p}=1.0)$ polymorphisms were in Hardy-Weinberg equilibrium among controls and cases while latest SNP (rs3025010) in RSA cases showedsignificant difference between expected and observed frequencies $(p=0.005)$ which is explained by the supposed disease state in cases which affect the equilibrium. The VEGF SNP rs2146323 showed homozygotic genotype in both case and control samples with CC genotypes (ancestral allele) (Tab. 2) therefore, it was removed from association analysis.

Lower minor allele frequencies (MAF) of rs3025039 (0.08), rs $1570360(0.15)$, rs3025010 (0.32) and rs2146323 (0.00) were seen in cases of MAF reported by HAP MAP database $(0.13,0.18$, 0.35 and 0.28 respectively). The $\chi^{2}$ test showed significant differences between case and control allele frequencies of rs 1570360 
Tab. 4. linkage disequilibrium analysis between pair VEGF SNPs studied.

\begin{tabular}{|c|c|c|c|c|c|c|c|c|}
\hline PairA & PairB & Allele count & D-value & $\mathrm{D}^{\prime}$-value & r-square & Chi-square & $\mathrm{df}$ & $\mathrm{p}$-value \\
\hline rs3025039 & rs1570360 & 400 & -0.003 & 0.530 & -0.046 & 0.846 & 1 & 0.357 \\
\hline rs3025039 & rs3025010 & 400 & 0.010 & 0.189 & 0.083 & 2.789 & 1 & 0.094 \\
\hline rs3025010 & rs 1570360 & 400 & 0.013 & 0.218 & 0.103 & 4.264 & 1 & 0.038 \\
\hline
\end{tabular}

Tab. 5. Analysis of molecular variance (AMOVA) based on VEGF gene polymorphism between two groups (cases and controls). $\mathrm{df}=\mathrm{de}-$ gree of freedom, $\mathrm{SS}=$ sum of square, $\mathrm{MS}=$ mean of square, Est. Var= estimated variance.

\begin{tabular}{lccccc}
\hline Source & df & SS & MS & Est. Var. & $\%$ \\
\hline Among Pops & 1 & 10.770 & 10.770 & 0.097 & $8 \%$ \\
Within Pops & 198 & 208.740 & 1.054 & 1.054 & $92 \%$ \\
\hline Total & 199 & 219.510 & & 1.151 & $100 \%$ \\
\hline Stat & Value & P(rand $\geq$ data) & & & \\
PhiPT & 0.084 & 0.001 & & & \\
\hline
\end{tabular}

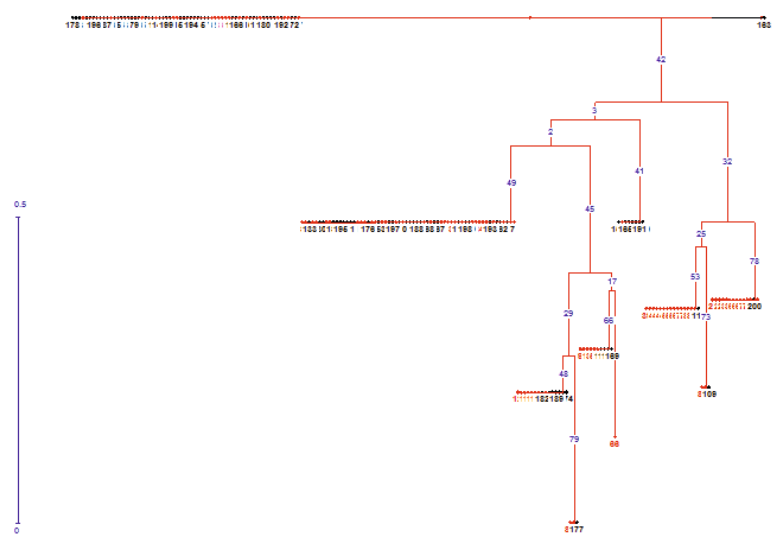

Fig. 1. Neighbouring Joining cluster based on VEGF gene SNPs. Blue numbers on branches indicate bootstraps. Red and black numbers indicate case and control sample numbers, respectively. and rs3025010 VEGF gene SNPs (p < 0.05) (Tab. 2) while, rs3025039 showed no significant difference $(p=0.56)$. The susceptibility of genotype frequencies was estimated by univariate and multivariate logistic regression analysis. In VEGF SNP rs 1570360 , homozygous wild-type genotype (GG) was considered as reference $(\mathrm{OR}=1.00)$ and heterozygous genotype $(\mathrm{AG})$ increased RSA risk $(\mathrm{OR}(95 \% \mathrm{CI})=0.01(0.03-0.29) ; \mathrm{p}<0.0001))($ Tab. 3). Logistic regression analysis confirmed an independent associations with RSA with rs3025010 under co-dominant $(\mathrm{p}=0.05)$, dominant ( $\mathrm{p}$ $=0.047)$ and over-dominant $(\mathrm{p}=0.016)$ inheritance models (Tab. 3 ). The association was not significant in rs3025039 (OR (95\% CI) $=0.73(0.33-1.60) ; \mathrm{p}<0.43]$ in heterozygous genotype.

Linkage disequilibrium (LD) based on $\mathrm{D}$ and $\mathrm{D}^{\prime}$ value, $r$ and chi square and associated p- value was analyzed between SNP pairs. These three SNPs and the LD block of the two genes are shown in Table 4. The VEGF SNP in intron 5 (rs3025010) showed to be linked to promoter region SNP (rs1570360) $\left(\mathrm{D}^{\prime}\right.$ value $=$ $0.218 ; \chi^{2}=4.264, p=0.03$ ) while no linkage was estimated in other SNP pairs.

Among seven estimated haplotype loci of VEGF gene, C-G$\mathrm{T}-\mathrm{C}$ was considered as wild-type haplotype with $\mathrm{OR}=1.00$. The estimated risk of $95 \% \mathrm{CI}$ for C-G-C-C haplotype was not shown to have significant association with RSA patients [OR $(95 \% \mathrm{CI})=$ $0.76(0.44-1.32), p=0.33$ ] while the rest haplotypes showed rare frequencies in both cases and controls with $\mathrm{OR}(95 \% \mathrm{CI})=0.23$ (0.11-0.45) and $\mathrm{p}<0.0001$ (supplemental Tab. 1).
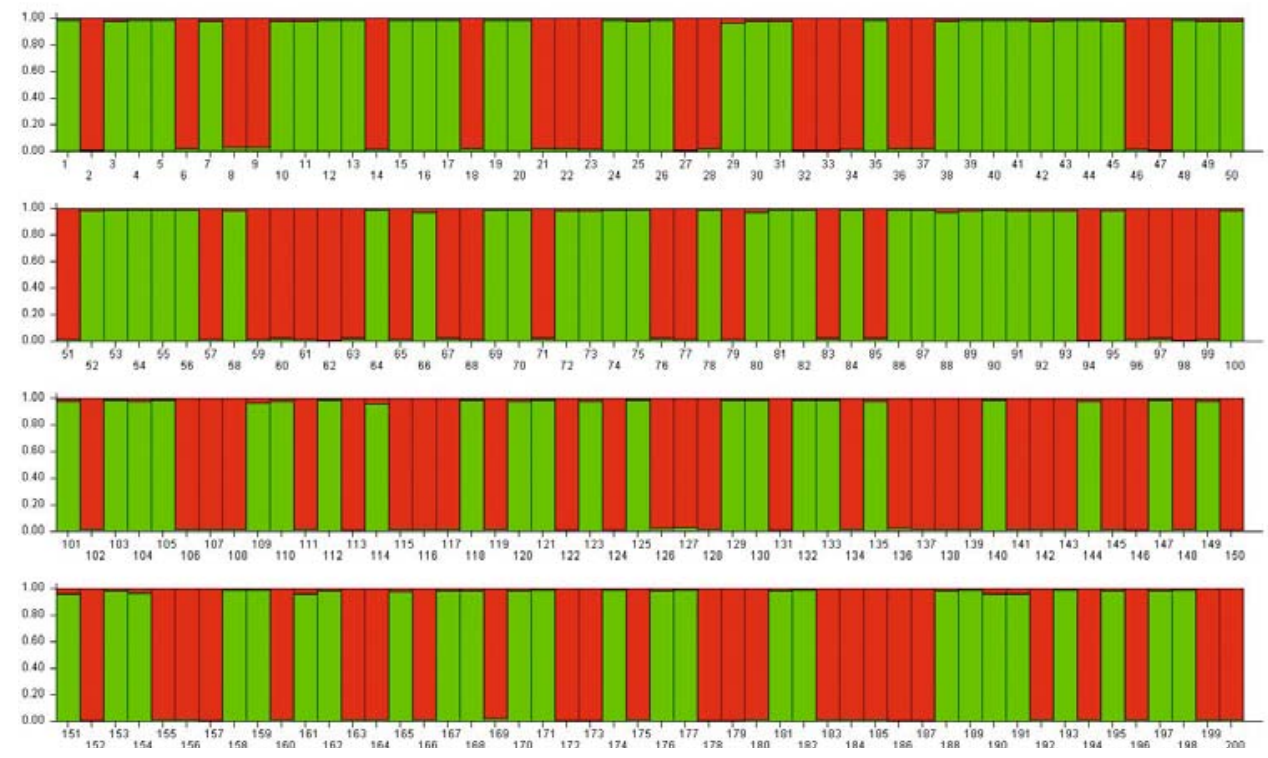

Fig. 2. STRUCURE plot based on four VEGF SNP sites. Different alleles showed in different colors. 1 to 100 = patient individuals; 101 to 200 $=$ control individuals. 
Tab. 6. K- means clustering based on VEGF gene polymorphisms. Clustering statistics from $k=1$ to $k=6$. * Best clustering according to Calinski \& Harabasz' pseudo-F: $k=6$, \& Best clustering according to Bayesian Information Criterion: $k=6$.

\begin{tabular}{|c|c|c|c|c|c|c|c|c|}
\hline $\mathrm{k}$ & $\mathrm{SSD}(\mathrm{T})$ & $\mathrm{SSD}(\mathrm{AC})$ & $\mathrm{SSD}(\mathrm{WC})$ & r-squared & pseudo-F & AIC & $\mathrm{BIC}$ & Rho \\
\hline 1 & 219.51 & 0 & 0 & 0 & 0 & 20.636 & 1083.578 & 0 \\
\hline 2 & 219.51 & 90.435 & 129.075 & 0.412 & 138.726 & -83.523 & 982.676 & 0.58 \\
\hline 3 & 219.51 & 134.22 & 85.29 & 0.611 & 155.009 & -164.33 & 905.106 & 0.71 \\
\hline 4 & 219.51 & 166.584 & 52.926 & 0.759 & 205.637 & -257.68 & 814.972 & 0.811 \\
\hline 5 & 219.51 & 181.883 & 37.627 & 0.829 & 235.652 & -323.811 & 752.035 & 0.866 \\
\hline $6 \& *$ & 219.51 & 196.632 & 22.878 & 0.896 & 333.482 & -421.195 & 657.823 & 0.917 \\
\hline
\end{tabular}

The study of genetic variation based on four nucleotide sites in VEGF gene resulted in high genetic polymorphism (70 \%) in both sample groups (case and control). Genetic parameters consisted of a number of effective alleles (Ne), Shannon index (I) and Nei's genetic diversity $(\mathrm{He})$ were calculated based on four SNP genotype frequencies in both cases and control (supplemental Tab. 2 ). Women with RSA showed higher genetic variation compared to control samples.

Analysis of molecular variance (AMOVA) was performed to estimate genetic differentiation between the two groups. In total, $92 \%$ of total variance was due to group variation and $8 \%$ variance between the case and control groups was observed with significant differences $(\mathrm{p}=0.001)$ (Tab. 5).

Grouping of genotypes by using Neighbor Joining clustering method is depicted in Figure 1. In general 6 distant groups were formed. Except for one cluster, the others showed no distinct separation between case and control samples. In the first cluster 32 case samples grouped together and separated from other samples except for four control samples (No. 109, 112, 117 and 200).

STRUCTURE result and Evano test also partitioned the studied case and controls samples in 6 genetically distinct clusters. The STRUCTURE plot of 200 individuals showed the presence of 2 kinds of allelic composition of two groups studied (different color in Figure 2). This result indicated that case and control samples gained similar combinations of alleles. In detail, the proportion of alleles in red color showed higher in control than in case samples.

The result of K-Means clustering is presented in Table 6. It showed the highest value of pseudo-F (333.482) for $\mathrm{k}=6$, and the lowest value of BIC (657.823) for $\mathrm{k}=6$. Therefore it showed $\mathrm{k}=6$ as the best fit for the optimal number of genetic subgroups in our studied materials.

\section{Discussion}

In the present study, association for the VEGF gene polymorphisms and the occurrence of idiopathic recurrent spontaneous abortion was studied by using four VEGF SNPs. The comparison of minor allele frequencies of both case and control samples and the global MAF revealed lower frequencies in all SNPs, although in HAPMAP database, Asian ethnicities including East Asia, Chinese and Japanese shows compatibility with frequencies in two SNPs studied (rs1570360 and rs3025010). The SNP +5092A/C located in intron region showed monomorphic genotype (CC) in our population study while in other ethnic populations the minor allele frequency (A allele) varied from 0.16 to 0.37 . Inconsistent results of different findings may stem from genetic variation in different populations and ethnicities.

The lack of the association with RSA and +936C/T (rs3025039, 3'UTR region) in the current study was also reported in Bahraini (Brazilian, 27), Greek (28) and Korean (29) population studies while Aggarwal et al (19) studied North Indians and it was in disagreement with previous studies and our findings. In the present study, we did not report $+936 \mathrm{~T}$ allele frequency of both case and controls. Homozygosity for this allele is also rare (0.8-4\%) in different populations $(19,28)$. The $+936 \mathrm{C} / \mathrm{T}$ SNP is located in 3'UTR region and was linked to altered VEGF expression in different studies (12, 30, 31). Galazios et al (32) and Magdoud et al (13) also reported that homozygotes carry the greatest risk of RSA patients because of VEGF protein levels.

For $-1154 \mathrm{G} / \mathrm{A}$, our results showed heterozygous genotype (GA) association with RSA. It was in agreement with the previous studies in Greek, American and Indian populations (19, 28, $32,33)$. It seems that the presence of allele (A) at +1154 produces the possibly of insufficient VEGF level because of low gene expression $(34,35)$. Furthermore, previous results and our findings are in disagreement with those of Eller et al (12). They reported no difference between homozygous genotype frequency (AA) in American women from Utah with RSA and controls. The same is true of Xing et al (18) the findings in Chinese Han population.

The VEGF SNP rs3025010 in different inheritance models were associated with RSA in our study, but no association was reported by $\mathrm{Su}$ et al (15), who studied Taiwanese Han women.

These obvious discrepancies may be attributed to differences in population ethnic background, sample size of study subjects, genetic diversity and lack of knowledge about the function of the gene and possible selection bias. Furthermore, the regulation of VEGF serum levels depends on local factors and systemic inflammatory molecules and they may be more significant than genetic factors (14). The RSA with multifactorial inheritance nature may be affected by different genetic factors which contribute to RSA pathogenesis including the VEGF SNPs identified, copy number variations, upstream promoter methylation, unknown regulatory factors and epistatic genes (14).

At the haplotype level, wild-type haplotype (C-G-T-C) showed the highest frequency among other 7 haplotypes. In our population, haplotypes with at least one minor allele among four SNPs showed significant associations $(\mathrm{P}<0.0001)$ with RSA pathogenesis except for $\mathrm{C}-\mathrm{G}-\mathrm{C}-\mathrm{C}$ haplotype $(\mathrm{P}=0.33)$. Magdoud et al (13) reported that homozygosity for some of the haplotypes in Bahraini population were associated with the lowest RSM risk in compari- 
Supplemental Table 1. Haplotype patterns with their frequencies in case and control samples, Odd ratio and $p$ value.

\begin{tabular}{|c|c|c|c|c|c|c|}
\hline Haplotype & Total & Case & Control & $\begin{array}{l}\text { Cumulative } \\
\text { frequency }\end{array}$ & $\begin{array}{c}\text { OR } \\
(95 \% \mathrm{CI})\end{array}$ & $\mathrm{p}$ value \\
\hline C-G-T-C & 0.616 & 0.547 & 0.681 & 0.616 & 1.00 & --- \\
\hline C-G-C-C & 0.230 & 0.223 & 0.237 & 0.846 & $0.76(0.44-1.32)$ & 0.33 \\
\hline C-A-T-C* & 0.047 & 0.082 & 0.015 & 0.893 & $0.23(0.11-0.45)$ & $<0.0001$ \\
\hline T-G-T-C* & 0.044 & 0.050 & 0.037 & 0.937 & - & - \\
\hline C-A-C-C* & 0.031 & 0.062 & 0.0001 & 0.969 & - & - \\
\hline T-G-C-C* & 0.024 & 0.029 & 0.022 & 0.994 & - & - \\
\hline T-A-C-C* & 0.006 & 0.005 & 0.004 & 1 & - & - \\
\hline
\end{tabular}

*rare haplotypes frequency

son to other haplotype pairs studied. Other haploview analyses in different ethnic populations introduced protective haplotypes in VEGF SNPs studied $(19,29)$. However, these findings are based on haplotypes with different VEGF SNPs combinations and we cannot provide exact comparison of our data.

In order to evaluate genetic variations in VEGF gene among population studied, genetic parameters were analyzed. Base on our data, high genetic variation was observed among both case and controls. In more detail, women with RSA showed higher heterozygosity compared to control samples. These results were also supported by haploview analysis. Neighbour Joining method grouped individuals to distinct groups. In cluster, some RSA individuals grouped distinctively because of their rare haplotypes (including one or more minor allele in profile). The $\mathrm{K}$ means clustering also estimated 6 groups as the best fit of genetic variations. It is similar to a number of haplotypes a well as groups in $\mathrm{NJ}$ analysis. AMOVA also supported differentiation between case and controls by using VEGF SNPs frequencies. In total, study of genetic variation in VEGF gene should be considered in association studies to provide more information about genetic pool of populations of different ethnic backgrounds and genetic variations.

In conclusion, our data have supported the findings of the previous studies by reporting increased risk of RSA in carriers of $-1154 \mathrm{~A}$ allele in promoter region. We also found that $\mathrm{C}$ allele in rs3025010 (intron 5) has an association with RSA pathogenesis. In haploview analysis, haplotypes with at least one minor allele were associated with the disease. In the current study, for the first time, genetic variation and genetic structure of VEGF gene has been reported among Iranian women population. Finally, we are aware that our data have some limitations. One of them is the lack of comprehensive evaluation of RSA subjects due to self-reported and economic limitations. The sample size is another common limitation of this kind of researches.

\section{References}

1. Brown S. Miscarriage and its associations. Semin Reprod Med 2008; 26: $391-400$.

2. Sierra S, Stephenson M. Genetics of recurrent pregnancy loss. Med Semin Reprod 2006; 24: 17-24.

3. Hodes-Wertz B, Grifo J, Ghadir S, Kaplan B, Laskin CA, Glassner $\mathbf{M}$ et al. Idiopathic recurrent miscarriage is caused mostly by aneuploid embryos. Fertil Steril 2012; 98: 675-680.
Supplemental Table 2. Genetic parameters based on four VEGF SNPs data. $\mathrm{Ne}=$ number of effective alleles, $\mathrm{I}=$ Shannon index, $\mathrm{He}=\mathbf{e x}-$ pected heterozygosity (Nei's genetic diversity), $\mathrm{SE}=$ standard error.

\begin{tabular}{lcccc}
\hline group & & $\mathrm{Ne}$ & $\mathrm{I}$ & $\mathrm{He}$ \\
\hline \multirow{2}{*}{ case } & Mean & 1.389 & 0.339 & 0.226 \\
& $(\mathrm{SE})$ & $(0.127)$ & $(0.093)$ & $(0.066)$ \\
\hline \multirow{2}{*}{ control } & Mean & 1.283 & 0.280 & 0.178 \\
& $(\mathrm{SE})$ & $(0.104)$ & $(0.084)$ & $(0.059)$ \\
\hline \multirow{2}{*}{ Total } & Mean & 1.336 & 0.310 & 0.202 \\
& $(\mathrm{SE})$ & $(0.081)$ & $(0.062)$ & $(0.044)$ \\
\hline
\end{tabular}

4. Finan RR, Al-Irhayim Z, Mustafa FE, Al-Zaman I, Mohammed FA, Al-Khateeb GM et al. Tumor necrosis factor-alpha polymorphisms in women with idiopathic recurrent miscarriage. J Reprod Immunol 2010; 84: $186-192$.

5. Metwally M, Saravelos SH, Ledger WL, Li TC. Body mass index and risk of miscarriage in women with recurrent miscarriage. Fertil Steril 2010; 94: 290-295.

6. O’Dwyer V, Monaghan B, Fattah C, Farah N, Kennelly MM, Turner MJ. Miscarriage after sonographic confirmation of an ongoing pregnancy in women with moderate and severe obesity. Obes Facts 2012; 5: 393-398.

7. Christiansen OB, Steffensen R, Nielsen HS, Varming K. Multifactorial etiology of recurrent miscarriage and its scientific and clinical implications. Gynecol Obstet Invest 2008; 66: 257-267.

8. Bautch VL. VEGF-directed blood vessel patterning: from cells to organism. Cold Spring Harb Perspect Med 2012; 2: a006452.

9. Lash GE, Innes BA, Drury JA, Robson SC, Quenby S, Bulmer JN. Localization of angiogenic growth factors and their receptors in the human endometrium throughout the menstrual cycle and in recurrent miscarriage. Hum Reprod 2012; 27: 183-195.

10. Tammela T, Berndt-Enholm B, Alitalo K, Paavonen K. The biology of vascular endothelial growth factors. Cardiovascul Res 2005; 65: $550-563$

11. Vincenti V, Cassano C, Rocchi M, Persico G. Assignment of the vascular endothelial growth factor gene to the human chromosome $6 \mathrm{p} 21.3$. Circulation 1996; 93: 1493-1495

12. Eller AG, Branch DW, Nelson L, Porter TF, Silver RM. Vascular endothelial growth factor-A gene polymorphisms in women with recurrent pregnancy loss. J Reprod Immunol 2011; 88: 48-52.

13. Magdoud K, Dendana M, Herbepin V, Hizem S, Ben Jazia K, Messaoudi S et al. Identification of specific vascular endothelial growth factor susceptible and protective haplotypes associated with recurrent spontaneous miscarriages. Hum Reprod 2012; 27 (5): 1536-1541. 


\section{0-86}

14. Almawi WY, Saldanha FL, Mahmood NA, Al-Zaman I, Sater MS, Mustafa FE. Relationship between VEGFA polymorphisms and serum VEGF protein levels and recurrent spontaneous miscarriage. Hum Reprod 2013; 28 (10): 2628-2635.

15. Su MT, Lin SH, Chen YC. Genetic association studies of angiogenesis- and vasoconstriction related genes in women with recurrent pregnancy loss: a systematic review and meta-analysis. Hum Reprod Update 2011 a; 17(6): 803-812.

16. Su MT, Lin SH, Lee IW, Chen YC, Kuo PL. Association of polymorphisms/haplotypes of the genes encoding vascular endothelial growth factor and its KDR receptor with recurrent pregnancy loss. Hum Reprod 2011 b; 26 (4): 758-764.

17. Yalcintepe SA, Silan F, Hacivelioglu SO, Uludag A, Cosar E, Ozdemir O. Fetal VEGF Genotype is More Important for Abortion Risk than Mother Genotype. Int J Mol Cell Med 2014; 3 (2): 88-94.

18. Xing X, Junhao-Yan J, Zhao Y, Li-You L, Bian Y, Chen ZJ. Association of vascular Endothelial Growth Factor Gene Polymorphisms with Recurrent Spontaneous Abortion in Chinese Han Women. Am J Reprod Immunol 2011; 65: 521-525.

19. Aggarwal S, Parveen F, Faridi RM, Phadke S, Borkar M, Agrawal S. Vascular endothelial growth factor gene polymorphisms in North Indian patients with recurrent miscarriages. Reprod BioMed Online 2011; 22: $59-64$

20. Ruggiero D, Dalmasso C, Nutile T, Sorice R, Dionisi L, Aversano M et al. Genetics of VEGF Serum Variation in Human Isolated Populations of Cilento: Importance of VEGF Polymorphisms. PLoS ONE 2011; 6(2): e16982. doi:10.1371/journal.pone.0016982.

21. Stirrat GM. Recurrent miscarriage. Lancet 1990; 336: 673-675.

22. Sole' X, Guino' E, Valls J, Iniesta R, Moreno V. SNPStats: a web tool for the analysis of association studies. Bioinformatics 2006; 22 (15): $1928-1929$.

23. Weising $\mathbf{K}$, Nybom $\mathbf{H}$, Wolf $\mathbf{K}$, Kahl G. DNA Finger Printing in Plants. Second edition. 2005; 444 pp. CRC Press, Taylor \& Francis, New York.

24. Earl DA, von Holdt BM. STRUCTURE HARVESTER: a website and program for visualizing STRUCTURE output and implementing the Evanno method. Conserv Genet Resour 2012; 4: 359-361.
25. Evanno G, Regnaut S, Goudet J. Detecting the number of clusters of individuals using the software STRUCTURE: a simulation study. Mol Ecol 2005; 14: 2611-2620.

26. Meirmans PG, Van Tienderen PH. GENOTYPE and GENODIVE: two programs for the analysis of genetic diversity of asexual organisms. Mol Ecol Notes 2004; 4: 792-794.

27. Traina E, Daher S, Moron AF, Sun SY, Franchim CS, Mattar R. Polymorphisms in VEGF, progesterone receptor and IL-1 receptor genes in women with recurrent spontaneous abortion. J Reprod Immunol 2011; 88: $53-57$.

28. Papazoglou D, Galazios G, Papatheodorou K, Liberis V, Papanas N. Maltezos E. Vascular endothelial growth factor gene polymorphisms and idiopathic recurrent pregnancy loss. Fertil Steril 2005; 83: 959-963.

29. Lee HH, Hong SH, Shin SJ, Ko JJOhD, Kim NK. Association study of vascular endothelial growth factor polymorphisms with the risk of recurrent spontaneous abortion. Fertil Steril 2010; 93: 1244-1247.

30. Renner W, Kotschan S, Hoffmann C, Obermayer-Pietsch B, Pilger EA. Common $936 \mathrm{C} / \mathrm{T}$ mutation in the gene for vascular endothelial growth factor is associated with vascular endothelial growth factor plasma levels. J Vasc Res 2000; 7: 443-448.

31. Shim JY, Jun JK, Jung BK, Kim SH, Won HS, Lee PR et al. Vascular endothelial growth factor gene $+936 \mathrm{C} / \mathrm{T}$ polymorphism is associated with preeclampsia in Korean women. Am J Obstet Gynecol 2007; 197: e1-4.

32. Galazios G, Papazoglou D, Tsikouras P, Kolios G. Vascular endothelial growth factor gene polymorphisms and pregnancy. J Matern Fetal Neonatal Med 2009; 22: 371-378.

33. Coulam CB, Jeyendran RS. Vascular endothelial growth factor gene polymorphisms and recurrent pregnancy loss. Am J Reprod Immunol 2008; 59: 301-305.

34. Brogan IJ, Khan N, Isaac K, Hutchinson JA, Pravica V, Hutchinson IV. Novel polymorphisms in the promoter and 5' UTR regions of the human vascular endothelial growth factor gene. Hum Immunol 1999; 60: 1245-1249.

35. Shahbazi M, Fryer AA, Pravica V, Brogan IJ, Ramsay HM, Hutchinson IV et al. Polymorphisms in vascular endothelial growth factor gene is associated with increased risk of acute rejection in renal transplant recipients. J Am Soc Nephrol 2002; 1: 260-264. 